\title{
Hydrolysis of the Kitchen Waste through Dry Anaerobic Digestion - A Sustainable Environmental Practice for its Effective Management
}

\author{
Akanksha Agrawal \\ National Institute of Technology Raipur \\ Parmesh Kumar Chaudhari \\ National Institute of Technology Raipur \\ Prabir Ghosh ( $\sim$ prabirg.che@nitrr.ac.in ) \\ National Institute of Technology Raipur
}

\section{Research Article}

Keywords: Kitchen Waste, Hydrolysis, Leachate, Volatile fatty acids.

Posted Date: September 15th, 2021

DOI: https://doi.org/10.21203/rs.3.rs-770690/v1

License: (c) (i) This work is licensed under a Creative Commons Attribution 4.0 International License.

Read Full License 


\section{Abstract}

Population explosion coupled with rapid industrialization and urbanization has led to accumulation of food waste. Nearly, 1.3 billion tons of food waste has been encountered annually which poses a serious threat to the environment and human beings. Therefore, it has become imperative to look for the sustainable environmental practices to manage huge quantum of the waste. Anaerobic Digestion (AD) has emerged as techno economical viable solution with the aim of resource as well as energy recovery to combat the global energy crisis. In this study, an attempt has been made to study the hydrolysis of kitchen waste through dry anaerobic digestion being a suitable technology for treating organic wastes with varying composition and its superiority over the wet digestion. Laboratory scale batch studies were conducted on kitchen waste using three different dry fermenters of total volume 4-litre operating under mesophilic regime for duration of 32 days. The reactors were simultaneously operated with the retention time of 1 day, 2 day and 4 days, respectively. Comparative performance of leachate generation during hydrolysis reveals that reactor with 1-day retention time generates maximum leachate with high COD of $244 \mathrm{~g} / \mathrm{l}$ and VFA of $12.99 \mathrm{~g} / \mathrm{l}$. The specific rate constants for hydrolysis of kitchen waste through dry fermentation with retention time of 1 day, 2 days, 4 days were found to be $0.063,0.054$ and 0.027 day $^{-1}$, respectively.

\section{Introduction}

Cooked and uncooked kitchen waste both constitutes a major part of municipal solid waste. According to Food and Agriculture Organization of the United Nation, food waste accounts for $33 \%$ of the global food production which is 1.3 billion tons annually (FAO 2012). Due to economic and demographic expansion, primarily in Asian countries, the amount of FW is anticipated to increase multifold in next 25 years. According to reports, between 2005 and 2025, the yearly volume of urban FW in Asian countries might increase from 278 to 416 million tons (Melikoglu et al., 2013). Approximately, 1.4 billion hectares of arable land are utilized to produce food that is lost or squandered, moreover it also contributes to greenhouse gases ( $\mathrm{GHG}$ ) emission by accumulating around 3.3 billion tonnes of $\mathrm{CO}_{2}$ into the atmosphere annually. Kitchen waste due to its putrescible and biodegradable nature (volatile solids $85-95 \%$, moisture content 75-85\%) poses a serious disposal issues. In present scenario, it is generally sent to piggeries, disposed in sewers, disposed along with municipal solid waste, which ultimately goes to sanitary landfills or it is being incinerated posing serious threat to the environment as well as human beings (Agarwal et al. 2005; Kumar and Goel 2009; Kumar et al. 2009; Patnaik and Reddy 2009; Talyan et al. 2008). Incineration of the waste not only results in the emission of dioxins, but also reduces the economic value of the substrate (Katami et al. 2004). Moreover, this huge quantum of the waste if utilized in resourceful manner has a potential of generating $367 \mathrm{~m}^{3}$ of biogas per dry ton, about $65 \% \mathrm{CH}_{4}$ with an energy content of 6.025 to $9 \mathrm{TW} h / \mathrm{m}^{3}$ which will reduce our dependency on the fossil fuels and also combat energy crisis.

Anaerobic digestion is alluring and techno economical viable solution for the management of the kitchen waste which not only resolves the management of the huge pile of the waste but also addresses the 
world's energy security by generating biofuel along with nutrient recycling (Shin et el. 2001). Anaerobic digestion is broadly classified as dry digestion (TS $>20 \%$ ) and wet digestion (TS $<15 \%$ ) depending upon the presence of solid content in the substrate (Abbassi-Guendouz et al. 2012). It is well established fact that dry digestion is superior to wet digestion owing to its numerous benefits like high process efficiency, less reactor volume, less fresh water usage, more favorable energy balance and improved marketability of the digestate end product (Radwan et al. 1993; Lissens et al. 2001; Forster-Carneiro et al. 2008; Abouelenien et al. 2009). However, long degradation time and accumulation of VFA which is attributed to high total solids reduces the process efficiency (Dhamodharan et al. 2015) and require high F/1 ratio (Dhamodharan et al. 2015; Chen et al. 2008). Furthermore, due to lack of comphrensive knowledge about dry digestion in contrast to wet digestion and the perceived operational complexity to achieve stable production make it still unpopular. Stage separation in the dry AD plays a vital role for addressing above mentioned difficulties during the operation to achieve optimized stable processes. Researches are directed towards anaerobic digestion of solid or semi-solid waste through two-phase anaerobic digestion, with first phase the hydrolysis/ acidification step to obtain leachate, which fed to the second phase for methanization in high strength anaerobic reactors (Guerrero 1999). Dry fermentation process is considered as superior process than slurry phase or thermal liquefaction process used in acidogenic reactor. In two phase, physical separation of the process helps in optimizing the first phase, which is many times the rate-limiting step. It also allows the maintenance of appropriate densities of the acid and methane formers in separate reactors which enable maximization of the rates of acidification and methanogenesis by applying optimal operational conditions, determined by the metabolic and biokinetic properties of both groups (Dinopoulou et al. 1988; Zhang et al. 2005). The maximum amount of energy in the form methane from biomethanation of solid organic residue depends on the extent of solubilization of the organic residues. The yield is directly related to the extent of solubilization of a substrate, but a rate of gas production will depend on the slowest of the three steps, namely, solubilization, acidogenesis and methanogens. Methanogenesis is the slowest step, whereas hydrolysis and solubilization may be the rate limiting steps (Jash and Ghosh 1996). Jash \& Ghosh (1996) reported kinetic study on solubilization rate by correlating the results in terms of biodegradable suspended particles of some organic residues for different variables. In this research, an attempt has been made to study the acidogenesis of kitchen waste through dry fermentation process at varying retention time to generate better leachate production which can be utilized in the second phase of $A D$, i.e. methanogenesis. This work also aims at studying the solubilization rate during hydrolysis of kitchen waste.

\section{Materials And Methods}

\section{Dry fermentation Unit}

The dry fermentation unit used for leachate generation is made of PVC material having total 4 litre volume with 2 litre working volume for kitchen waste, 1-liter volume portion at the top for feeding dilution water and 1 litre volume for storing the leachate collected at the bottom. A screen of fine nylon mesh was placed at height of $17 \mathrm{~cm}$ from the bottom inside the reactor preventing solid particles in leachate. An 
outlet of $6 \mathrm{~mm}$ diameter was provided to the end cap to collect leachate. A 5 litre plastic container was used for comparative studies on leachate production for different conditions provided.

\section{Kitchen Waste}

Kitchen waste collected from Central dining hall (CDH) of the girl's hostel of COEP, Pune India was used to prepare the feedstock for experiments. The kitchen waste was then subjected to mechanical pulverization using kitchen blender for 1 minute. The proportion used for the present study was $50 \%$ vegetable waste and $50 \%$ of leftover food waste. Physiochemical properties of the feedstock and inoculum are presented in Tables 1 and 2. For inoculation, leachate was obtained from the mesophilic digester treating food waste in the same campus. The ratio of inoculum to kitchen waste was 1:4 by volume. Tap water was used as dilution water added from the top.

\section{Table I: Physiochemical properties of the feedstock}

\begin{tabular}{|ll|}
\hline Parameters & Value \\
\hline Particle size & $<2 \mathrm{~mm}$ \\
\hline TS $(\%)$ & 22.16 \\
\hline VS (\% of TS) & 97.93 \\
\hline SS (\% of TS) & 88.13 \\
\hline Moisture content $(\%)$ & 84.2 \\
\hline PH & 5.89 \\
\hline VFA $(\mathrm{mg} / \mathrm{l})$ & 862.82 \\
\hline COD $(\mathrm{mg} / \mathrm{l})$ & $2,42,333$ \\
\hline Alkalinity $\left(\mathrm{mg} / \mathrm{l}\right.$ of $\left.\mathrm{HCO}_{3}\right)$ & 440 \\
\hline Density $\left(\mathrm{kg} / \mathrm{m}^{3}\right)$ & 888.6 \\
\hline
\end{tabular}

Table Il: Physiochemical properties of the Inoculum 


\section{Analytical methods}

\begin{tabular}{|ll|}
\hline Parameters & Value \\
\hline TS $(\%)$ & 2.27 \\
\hline VS (\% of TS) & 90.28 \\
\hline SS (\% of TS) & 41.70 \\
\hline pH & 3.18 \\
\hline VFA(mg/l) & 1885.62 \\
\hline $\operatorname{COD}(\mathrm{mg} / \mathrm{l})$ & $1,06,000$ \\
\hline
\end{tabular}

The samples of leachate obtained through the reactor were collected daily during the experiments and analyzed immediately for various parameters viz. pH, VFA, COD as per the methods suggested in Standard Methods of water and wastewater examination, APHA 2002. The sample of kitchen waste and the feed stock characteristics were determined as per procedure prescribed in IS 9235-1979.

\section{Experimental Procedure}

A set of three reactors was used for this study. Each reactor was fed with the same feedstock and inoculated with leachate from previous successful reactor. Study on leachate production was conducted by operating the reactors for different retention time given as

- Reactor 1 (R1): 1-day retention time.

- Reactor 2 (R2): 2 days' retention time.

- Reactor 3 (R3): 4 days' retention time.

The rate at which water added per day during this study in each reactor

- The first stage (8days): $25 \mathrm{ml}$.

- The second stage (8 days): $100 \mathrm{ml}$.

- The third stage (8 days): $250 \mathrm{ml}$.

- The fourth stage (8 days): $400 \mathrm{ml}$.

The amount of water added in R2 is double of R1, but at alternate days whereas the amount of water added in R3 is about 4 times at 4 days' interval. Leachate from each reactor were collected and analyzed after respective retention time. This procedure was repeated for 32 days from the starting of reactor.

\section{Results And Discussions}




\section{Influence of operating parameters on Hydrolysis and Acidogenesis}

Main end product of the first phase of the biomethanation is the formation of the volatile fatty acid (VFA). The formation of VFA is influenced by many factors such as $\mathrm{pH}$, retention time, and composition of the substrate; therefore it becomes imperative to understand the influence of these parameters as this will help in better designing of the process. In this research, performance of the dry fermentation unit for different retention time was analyzed for the quality of leachate obtained. The variations in the $\mathrm{pH}, \mathrm{VFA}$, COD of leachate from reactors R1, R2, and R3 were studied and are presented in the Figs. 2,3,4,5 and 6, respectively.

\section{Variation of $\mathrm{pH}$}

$\mathrm{pH}$ of the reactor plays crucial role in the degradation of food waste through microbial activity. Ideal pH range for hydrolysis and acidogenesis for the degradation of organic fraction of solid waste is considered to be from 4 to 6 ( $\mathrm{Li}$ and Fang 2007). The variation of $\mathrm{pH}$ of the leachate obtained through dry fermentation unit is shown in Fig. 1. It was observed that in the initial stage, the pH decreases up to 3.51 and then increases gradually to 5.5 in R1, which is in consistent with the earlier result reported (Selvam et al. 2010; Xu et al. 2011; Xu et al. 2012). Whereas a minimum value of $\mathrm{pH}$ of 3.52 and 3.48 was observed in leachate from R2 and R3 on day 8. The lower $\mathrm{pH}$ values of the reactors are attributable to the production of formic acid and lactic acid due to their low pKa values, i.e. 3.77 and 3.86, respectively. Furthermore, due to presence of high concentration of the soluble organics in kitchen waste result in $\mathrm{pH}$ drop. Formation of the intermediate products such as acetate, lactate, formate, succinate and ethanol occur during acid fermentation, as a result of the enzymatic hydrolysis by the members of the family Enterobacteriaceae, Clostridia and lactic acid bacteria (LAB). LAB are the dominant microbial archea during the degradation of food waste in the mesophilic temperature regime (Wang et al. 2001). However, if $\mathrm{pH}$ is adjusted using alkaline solution it reduces the dominance of $L A B$ by enriching it with the coliform bacteria and Clostridia.

\section{Variation of VFA concentration of leachate during operation Period}

Rate of the volatile acids production is directly proportional to the digestion period. In the initial stage, rapidly degradable materials like grains are liable to cause VFA accumulation. This brings about severe inhabitation in acidic fermentation by reducing the $\mathrm{pH}$ of the reactor, thus ultimately results in the inhabitation of biogas production (Shin et al. 2001). Variation of VFA concentration of leachate during operation period is shown in Fig. 2. The first peak on day 3 was the result of grains degradation $(12.993 \mathrm{~g} / \mathrm{l})$. It was observed that the degradation of cellulose increases at high retention time and the degradation of protein increases at both high retention time and neutral pH (Noike et al. 1985). However, with the improvement of the $\mathrm{pH}$ of the system, VFA production again shoots up to $(11.257 \mathrm{~g} / \mathrm{l})$, indicating the enhanced degradation of vegetables. From the graph, it can be concluded that the reactor with shorter 
retention time achieves better acidification rate as it does not support the accumulation of VFA. The decline trend of VFA production after day 17 may be attributed to the shortage of the sufficient substrate available for the microbial consortia. The variation of cumulative VFA during the digestion is represented by Fig. 3. It indicates that the rate of VFA production increases during the initial period and then the rate decreases which is mainly attributed to the $\mathrm{pH}$ and acidification efficiency of microbes, as at lower $\mathrm{pH}$ it results in the activation of the enzymes necessary for the microbial community to perform degradation (Tembhurkar and Mhaisalkar 2007). The cumulative value of VFA in R1 indicates a smoother trend with higher accumulated VFA, whereas the VFA generated in R2 is comparatively less and R3 is least. The similar trend was exhibited in the past studies by (Tembhurkar and Mhaisalkar 2007; Xu et al. 2011).

\section{Variation of COD of leachate during operation Period}

From Fig. 4, a biphasic pattern of COD leaching can be observed. COD concentrations of the collected leachate during initial days of operation were found to be higher ranging from $72 \mathrm{~g} / \mathrm{L}$ to $185 \mathrm{~g} / \mathrm{L}$ in reactor R1, after that they start depleting gradually. The initial high rate of COD leaching was partially attributed to the water-soluble fraction of food waste itself and it also depends on the substrate concentration. Decline in the trend of the COD may be attributed to the wash out of the water soluble fraction of the food waste from reactor (Xu et al. 2012; Xu et al. 2014). The value of COD from the leachates obtained from all the reactors show sudden peaks may be because of accidental slipping of the hydrolyzed waste. It was observed that the higher value of COD during initial days is because of the hydrolyzed material getting washed as the leachates which impart high rate of COD. The rate of COD accumulation of the leachate can be better studied by plotting the cumulative diagram COD which is shown in Fig. 5. The rate of accumulation of COD of R3 is lowest than R2 then R1 due to the conditions prevailing in these reactors and it is mostly attributed to the lower $\mathrm{pH}$ of the system which will hamper degree of acidification of the system and it will be in the order of $\mathrm{R} 3<\mathrm{R} 2<\mathrm{R} 1$.

\section{Solubilization rate of kitchen waste during hydrolysis}

The maximum amount of energy in the form of methane obtainable from a solid organic residue by biomethanation depends on the extent of solubilization of the organic residues. The yield is directly related to the extent of solubilization of a substrate, but the rate of gas production will depend on the slowest of the three steps, namely, solubilization, acidogenesis and methanogenesis. Methanogenesis is the slowest step, whereas hydrolysis and solubilization may be the rate limiting steps (Jash and Ghosh 1996).

The solubilization rate decreases with the operation period. It may be due to the high content of rapidly degradable matter. The solubilization rate of substrate decreased in the following order: R1 $>$ R2 $>$ R3. The rate of solubilization decreases with an increase of substrate concentration due to lowering of $\mathrm{pH}$. It is also evident that at higher substrate concentration, the solubilization rate is initially higher, resulting in a higher concentration of soluble substrate amenable to acidogenesis leading to lowering of ph. Because of lowering of $\mathrm{pH}$, the solubilization rate slows down subsequently steps (Jash and Ghosh 1996). 
The solubilization rate of the kitchen waste was determined for reactor R1, R2 and R3. The first phase of hydrolysis and acidification of the kitchen waste was assumed to follow the first order rate of reaction, which is given as equation,

$-\mathrm{d} C / \mathrm{d} t=k C$,

$t=-(1 / k) \ln (C / C 0)$,

Where $k=$ first-order specific rate constant $\left(\right.$ day $\left.^{-1}\right), C=$ COD concentration of kitchen waste $(\mathrm{mg} / \mathrm{l})$ at time $t, C O=$ initial COD concentration of kitchen waste $(\mathrm{mg} / \mathrm{l})$ at zero time.

The data is plotted in Figs. 6, 7 \& Fig. 8 to determine specific rate constant for R1, R2, R3, respectively. The specific rate constant was found to be maximum 0.063 for R1 and that is for R2 is 0.054 and R3 is 0.027 indicating that daily addition of water improves the solubilization process. The solubilization rate of the kitchen waste of reactor R1 is higher than of reactor R2 and R3, respectively.

\section{Conclusions}

The rate of leachate extraction is higher up to initial 10 days and then it decreases in later stage. The $\mathrm{pH}$ of the leachate drops down up to 6 to 8 days because of fast accumulation of VFA with no significant buffering capacity and then regains in the later stage may be due to washout of acidic content and dilution. The rate of VFA extraction is higher in initial stage and then decreases. For the retention time of 1 day, reactor R1 shows better results than R2 and R3 with higher retention time. Hence, retention time of 1 day should be adopted when dry fermentation is to be used as preprocessing process prior to methanization of kitchen waste. The COD value of leachate obtained increases in initial 8 to 10 days and then it goes on decreasing beyond 10 days. The $\mathrm{pH}$ of $\mathrm{R} 3$ is lower than $\mathrm{R} 2$ then $\mathrm{R} 1$ as indicated because of low $\mathrm{pH}$, the efficiency of acidification process is least at $\mathrm{R} 3<\mathrm{R} 2<\mathrm{R} 1$. The first order rate constant was reported maximum 0.063 for $\mathrm{R} 1$ and 0.054 for $\mathrm{R} 2$ and 0.027 for R3 indicating that daily addition of water improves the solubilization process.

\section{Declarations}

Author contribution Conceptualization, Methodology and investigation: Akanksha Agrawal.

Writing original draft and supervision: P K Chaudhari. Prabir Ghosh: conceptualization, review, editing and supervision

Funding Not applicable

Data Availability Not applicable

Ethical approval Not applicable. 
Consent to participate Not applicable.

Consent for publication Written informed consent for publication was obtained from all participants.

Competing interests The authors declare no competing interests.

\section{References}

1. Abbassi-Guendouz, A., Brockmann, D., Trably, E., Dumas, C., Delgenès, J. P., Steyer, J. P., \& Escudié, R. (2012). Total solids content drives high solid anaerobic digestion via mass transfer limitation. Bioresource technology, 111, 55-61.

2. Abouelenien, F., Nakashimada, Y., \& Nishio, N. (2009). Dry mesophilic fermentation of chicken manure for production of methane by repeated batch culture. Journal of bioscience and bioengineering, 107(3), 293-295.

3. Agarwal, A., Singhmar, A., Kulshrestha, M., \& Mittal, A. K. (2005). Municipal solid waste recycling and associated markets in Delhi, India. Resources, Conservation and Recycling, 44(1), 73-90.

4. American Public Health Association, American Water Works Association, Water Pollution Control Federation, \& Water Environment Federation. (1912). Standard methods for the examination of water and wastewater (Vol. 2). American Public Health Association..

5. Cho, J. K., Park, S. C., \& Chang, H. N. (1995). Biochemical methane potential and solid state anaerobic digestion of Korean food wastes. Bioresource technology, 52(3), 245-253.

6. Dhamodharan, K., Kumar, V., \& Kalamdhad, A. S. (2015). Effect of different livestock dungs as inoculum on food waste anaerobic digestion and its kinetics. Bioresource technology, 180, 237-241.

7. Dinopoulou, G., Rudd, T., \& Lester, J. N. (1988). Anaerobic acidogenesis of a complex wastewater: I. The influence of operational parameters on reactor performance. Biotechnology and bioengineering, 31(9), 958-968.

8. FAO, Towards the Future we Want: End Hunger and Make the Transition to Sustainable Agricultural and Food Systems, Food and Agriculture Organization of the United Nations Rome, 2012.

9. Forster-Carneiro, T., Pérez, M., \& Romero, L. I. (2008). Influence of total solid and inoculum contents on performance of anaerobic reactors treating food waste. Bioresource technology, 99(15), 69947002.

10. Ghanem, I. I. I., Guowei, G., \& Jinfu, Z. (2001). Leachate production and disposal of kitchen food solid waste by dry fermentation for biogas generation. Renewable energy, 23(3-4), 673-684.

11. Guerrero, L., Omil, F., Mendez, R., \& Lema, J. M. (1999). Anaerobic hydrolysis and acidogenesis of wastewaters from food industries with high content of organic solids and protein. Water Research, 33(15), 3281-3290.

12. Han, S. K., \& Shin, H. S. (2002). Enhanced acidogenic fermentation of food waste in a continuousflow reactor. Waste management \& research, 20(2), 110-118. 
13. Jash, T., \& Ghosh, D. N. (1996). Studies on the solubilization kinetics of solid organic residues during anaerobic biomethanation. Energy, 21(7), 725-730.

14. Katami, T., Yasuhara, A., \& Shibamoto, T. (2004). Formation of dioxins from incineration of foods found in domestic garbage. Environmental science \& technology, 38(4), 1062-1065.

15. Kayhanian, M. (1995). Biodegradability of the organic fraction of municipal solid waste in a highsolids anaerobic digester. Waste Management \& Research, 13(2), 123-136.

16. Kumar, K. N., \& Goel, S. (2009). Characterization of municipal solid waste (MSW) and a proposed management plan for Kharagpur, West Bengal, India. Resources, Conservation and Recycling, 53(3), 166-174.

17. Kumar, S., Bhattacharyya, J. K., Vaidya, A. N., Chakrabarti, T., Devotta, S., \& Akolkar, A. B. (2009). Assessment of the status of municipal solid waste management in metro cities, state capitals, class I cities, and class II towns in India: An insight. Waste management, 29(2), 883-895.

18. Li, C., \& Fang, H. H. (2007). Fermentative hydrogen production from wastewater and solid wastes by mixed cultures. Critical reviews in environmental science and technology, 37(1), 1-39.

19. Lissens, G., Vandevivere, P., De Baere, L., Biey, E. M., \& Verstraete, W. (2001). Solid waste digestors: process performance and practice for municipal solid waste digestion. Water science and technology, 44(8), 91-102.

20. Melikoglu, M., Lin, C. S. K., \& Webb, C. (2013). Analysing global food waste problem: pinpointing the facts and estimating the energy content. Central European Journal of Engineering, 3(2), 157-164.

21. Noike, T., Endo, G., Chang, J. E., Yaguchi, J. I., \& Matsumoto, J. I. (1985). Characteristics of carbohydrate degradation and the rate-limiting step in anaerobic digestion. Biotechnology and bioengineering, 27(10), 1482-1489.

22. Pattnaik, S., \& Reddy, M. V. (2010). Assessment of municipal solid waste management in Puducherry (Pondicherry), India. Resources, Conservation and Recycling, 54(8), 512-520.

23. Radwan, A. M., Sebak, H. A., Mitry, N. R., El-Zanati, E. A., \& Hamad, M. A. (1993). Dry anaerobic fermentation of agricultural residues. Biomass and Bioenergy, 5(6), 495-499.

24. Selvam, A., Xu, S. Y., Gu, X. Y., \& Wong, J. W. (2010). Food waste decomposition in leachbed reactor: role of neutralizing solutions on the leachate quality. Bioresource technology, 101(6), 1707-1714.

25. Shin, H. S., Han, S. K., Song, Y. C., \& Lee, C. Y. (2001). Multi-step sequential batch two-phase anaerobic composting of food waste. Environmental technology, 22(3), 271-279.

26. Shin, H. S., Han, S. K., Song, Y. C., \& Lee, C. Y. (2001). Performance of UASB reactor treating leachate from acidogenic fermenter in the two-phase anaerobic digestion of food waste. Water research, 35(14), 3441-3447.

27. Talyan, V., Dahiya, R. P., \& Sreekrishnan, T. R. (2008). State of municipal solid waste management in Delhi, the capital of India. Waste management, 28(7), 1276-1287.

28. Tembhurkar, A. R., \& Mhaisalkar, V. A. (2007). Studies on hydrolysis and acidogenesis of kitchen waste in two phase anaerobic digestion. Journal of the IPHE, India, 8(2), 10-18. 
29. Veeken, A. H. M., \& Hamelers, B. V. M. (2000). Effect of substrate-seed mixing and leachate recirculation on solid state digestion of biowaste. Water Science and Technology, 41(3), 255-262.

30. Xu, H. L., Wang, J. Y., Zhang, H., \& Tay, J. H. (2003). A comparative study of anaerobic digestion of food waste in a single pass, a leachate recycle and coupled solid/liquid reactors. Water science and technology, 47(1), 319-324.

31. Xu, S. Y., Karthikeyan, O. P., Selvam, A., \& Wong, J. W. (2012). Effect of inoculum to substrate ratio on the hydrolysis and acidification of food waste in leach bed reactor. Bioresource technology, 126, 425430.

32. Xu, S. Y., Lam, H. P., Karthikeyan, O. P., \& Wong, J. W. (2011). Optimization of food waste hydrolysis in leach bed coupled with methanogenic reactor: effect of $\mathrm{pH}$ and bulking agent. Bioresource technology, 102(4), 3702-3708.

33. Zhang, B., Zhang, L. L., Zhang, S. C., Shi, H. Z., \& Cai, W. M. (2005). The influence of pH on hydrolysis and acidogenesis of kitchen wastes in two-phase anaerobic digestion. Environmental technology, 26(3), 329-340.

\section{Figures}

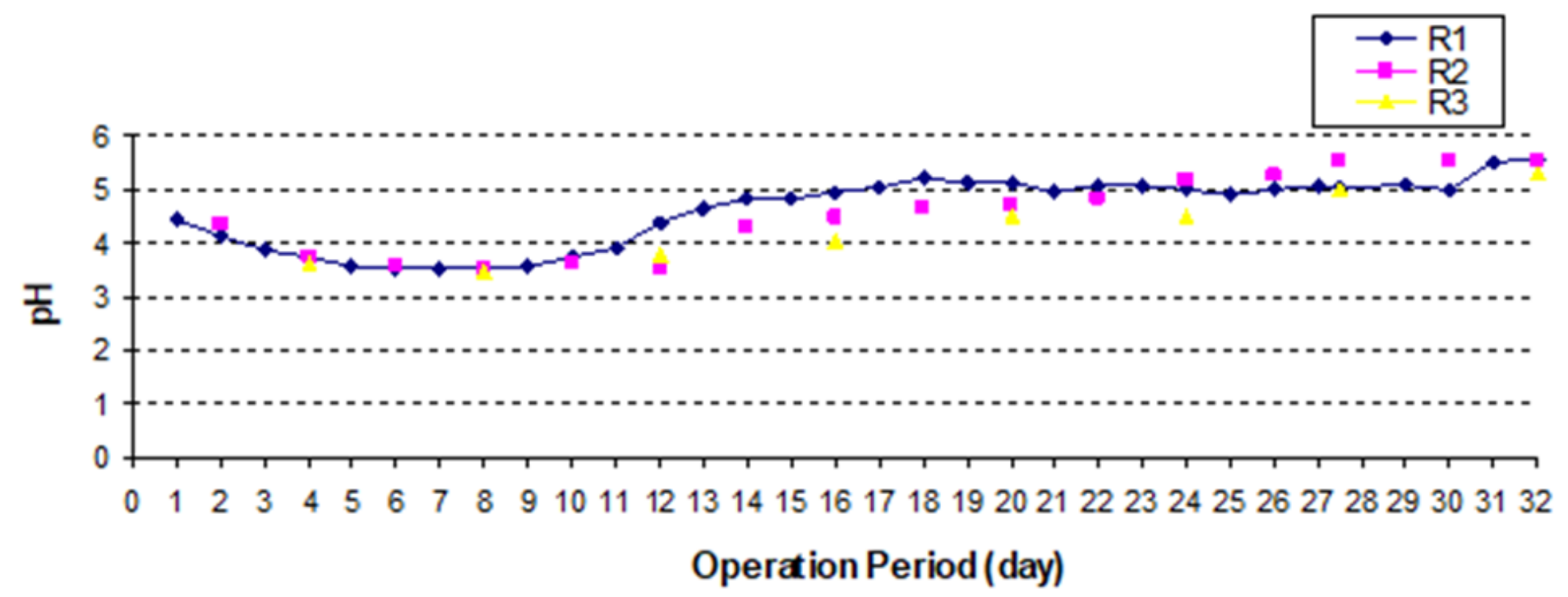

\section{Figure 1}

Variation of $\mathrm{pH}$ during the operation of the reactors. 


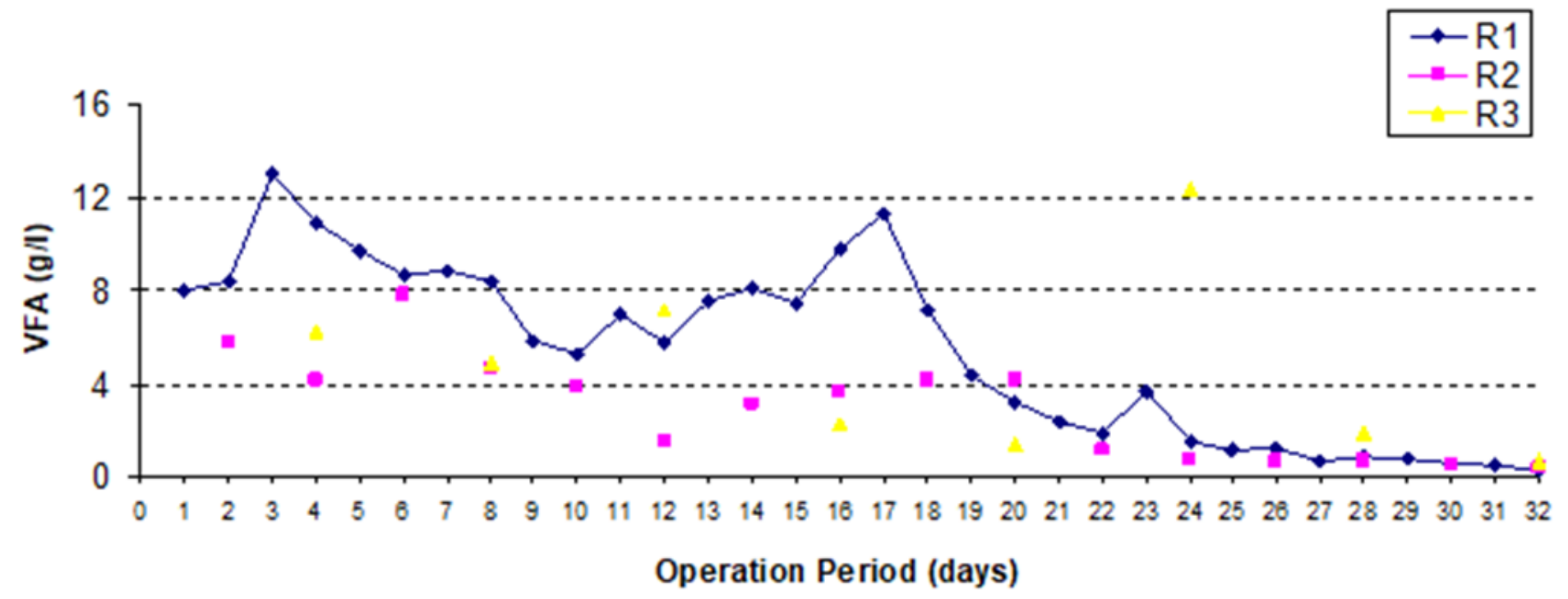

Figure 2

Variation of VFA during the operation of the reactors

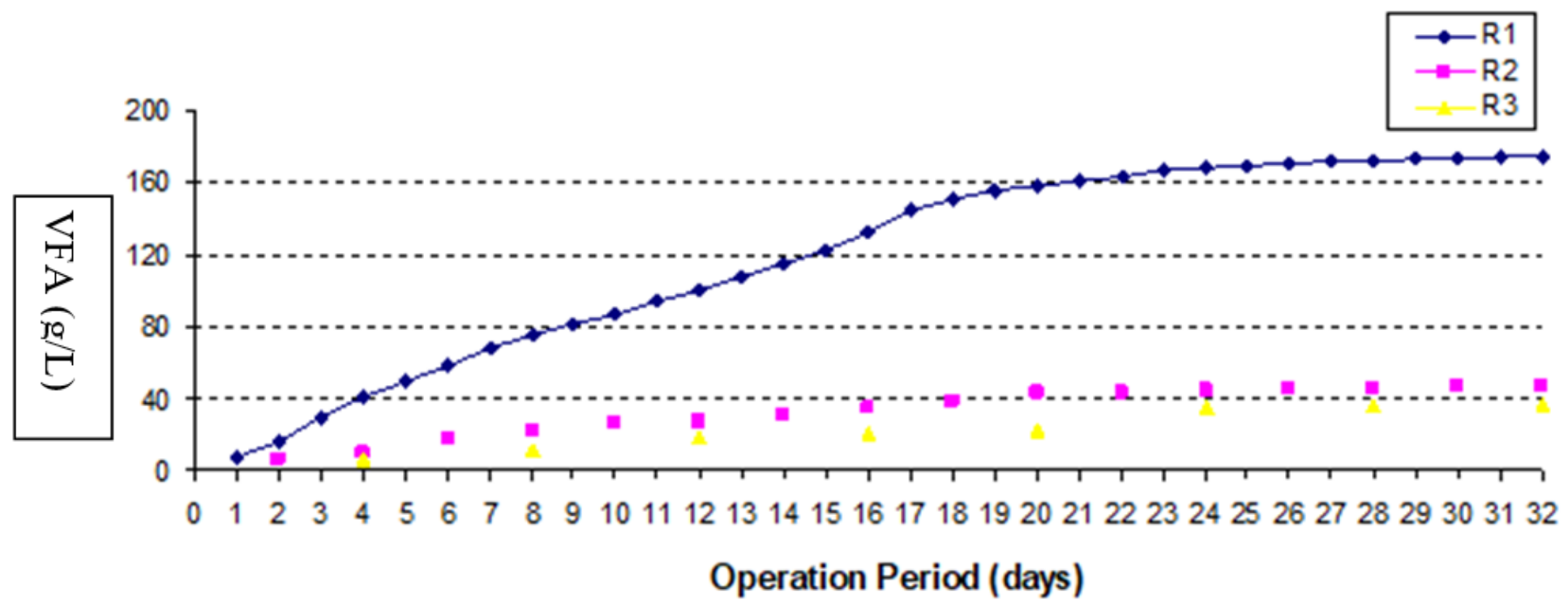

Figure 3

Variation of cumulative VFA during the operation of the reactors 


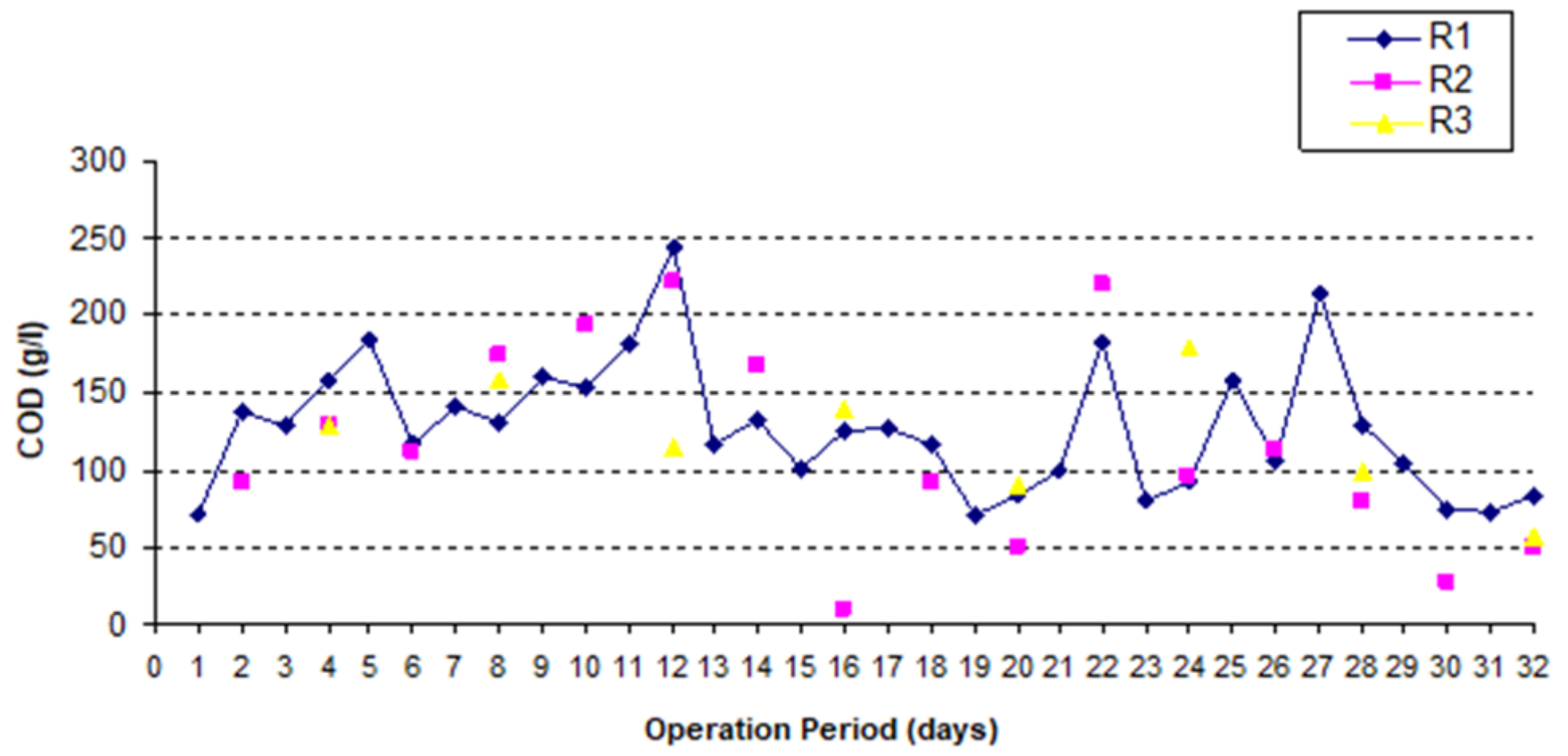

Figure 4

Variation of COD of the leachate during the operation of the reactors.

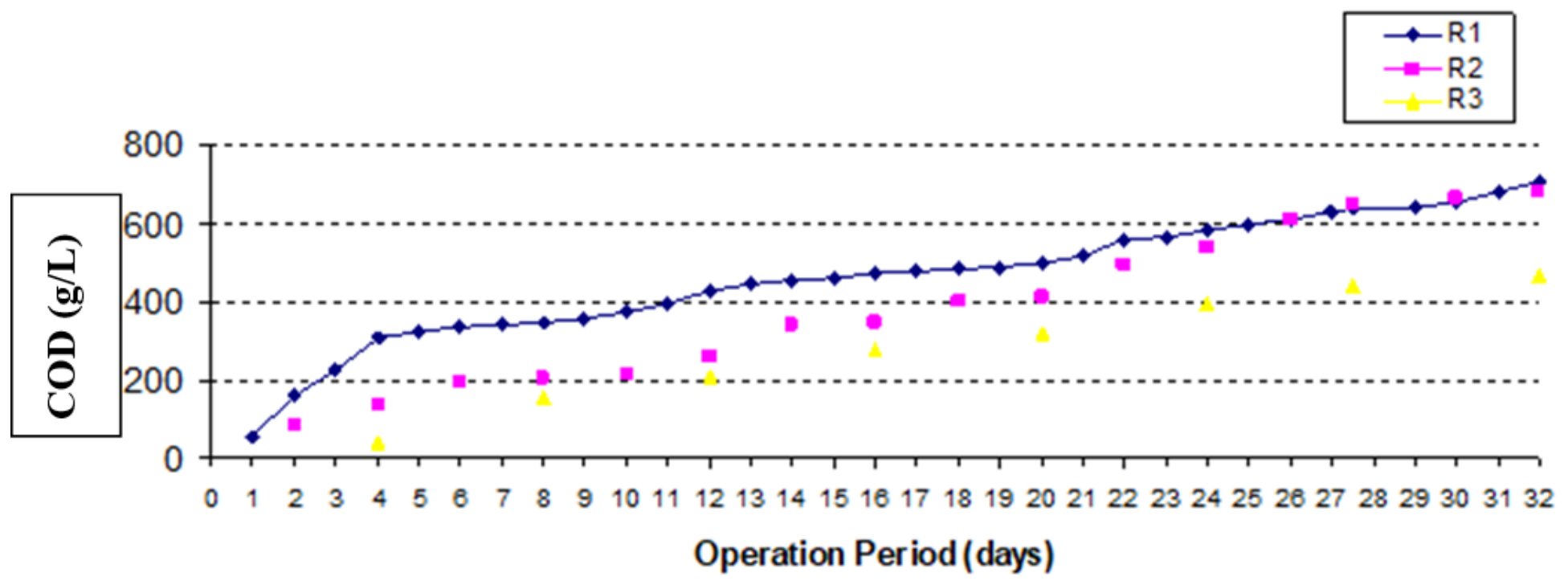

Figure 5

Variation of cumulative COD of the leachate during the operation of the reactors 


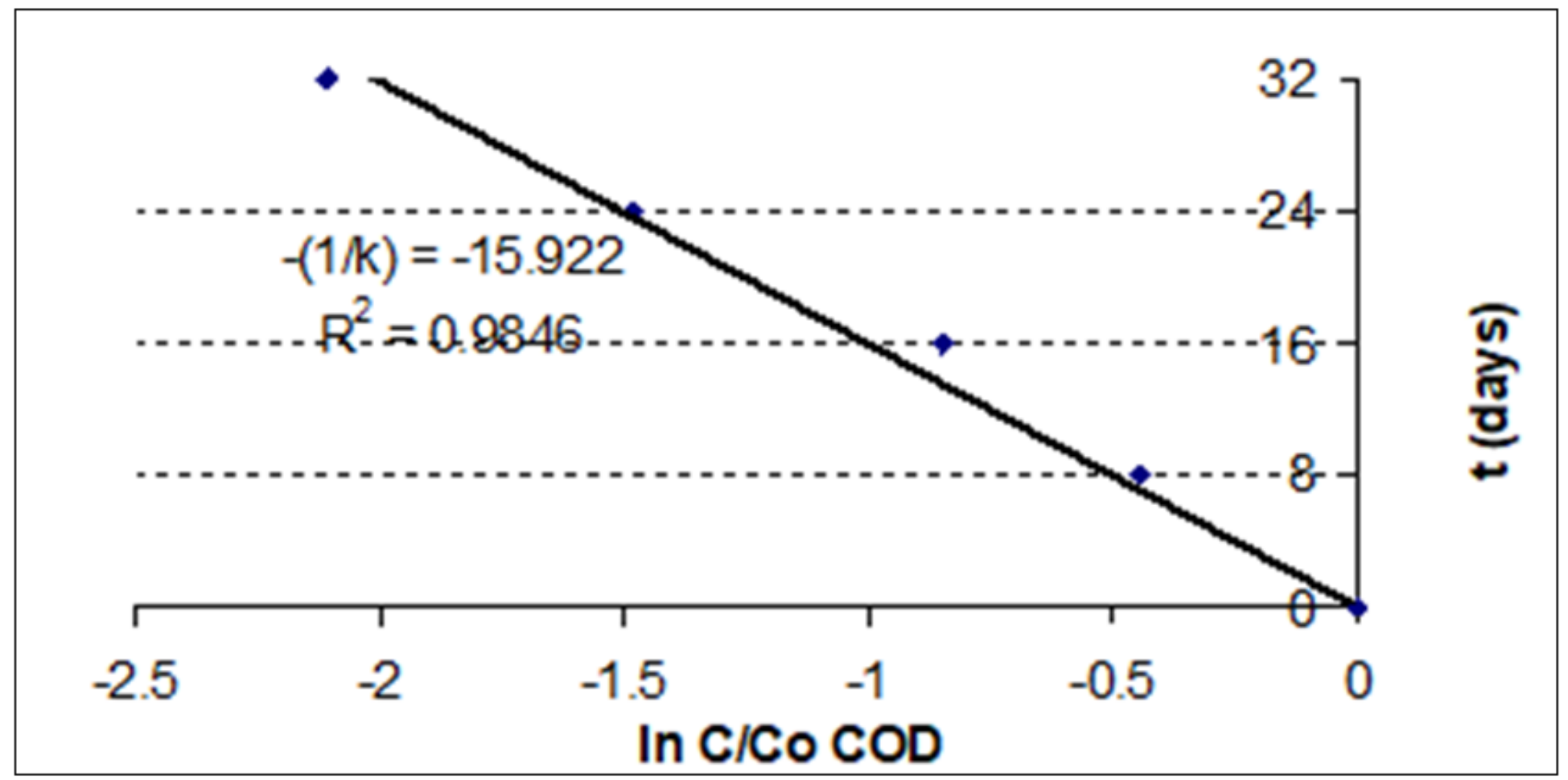

Figure 6

Specific rate constant during hydrolysis of kitchen waste in reactor R1

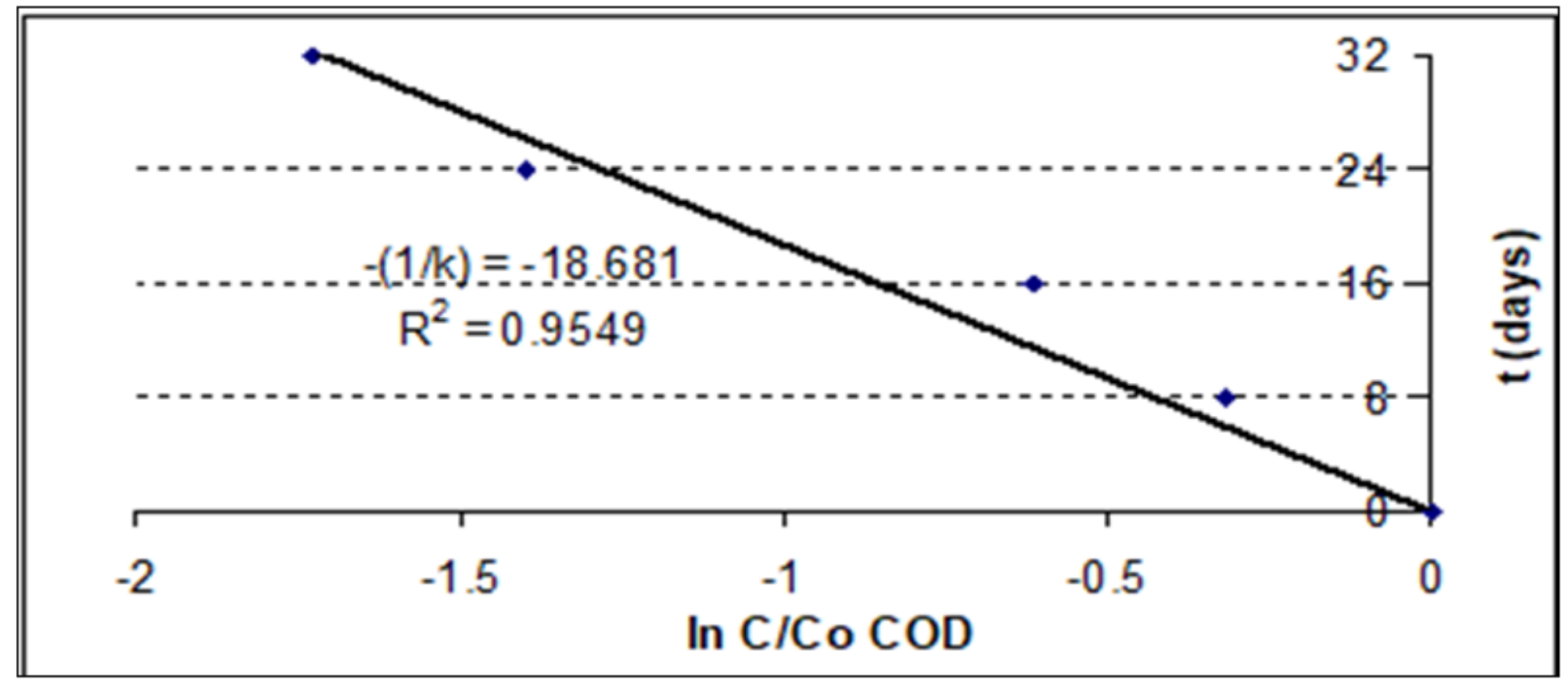

Figure 7

Specific rate constant during hydrolysis of kitchen waste in reactor R2 


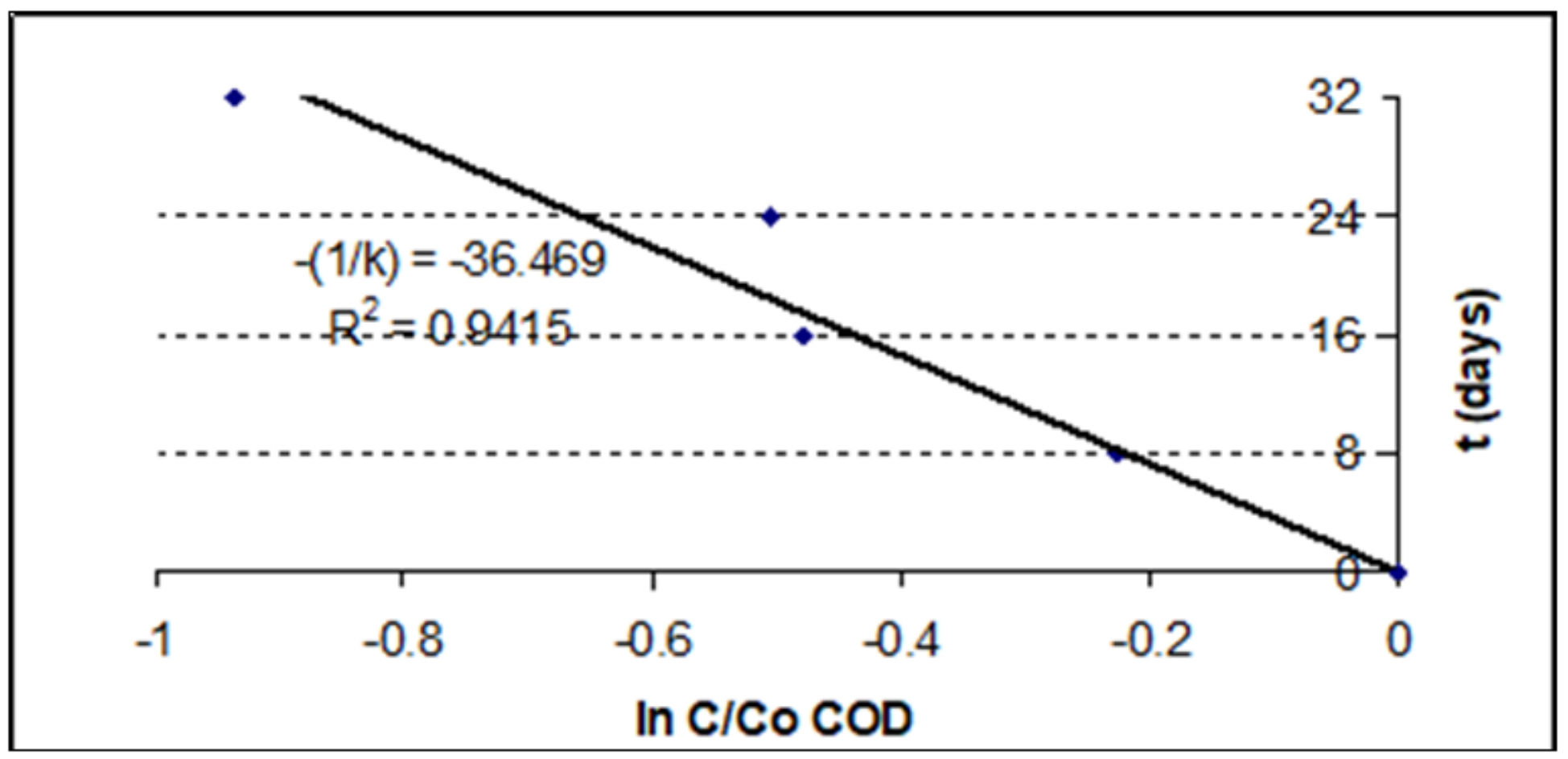

Figure 8

Specific rate constant during hydrolysis of kitchen waste in reactor R3 